\title{
The $G_{2} / M$ DNA damage checkpoint inhibits mitosis through Tyr15 phosphorylation of $\mathrm{p} 34^{c d c 2}$ in Aspergillus nidulans
}

\section{Xiang S.Ye, Russell R.Fincher, Alice Tang and Stephen A.Osmani ${ }^{1}$}

The Weis Center for Research, Geisinger Clinic, Danville, PA 17822 , USA

${ }^{1}$ Corresponding author

It is possible to cause $\mathbf{G}_{2}$ arrest in Aspergillus nidulans by inactivating either $\mathrm{p3}^{\text {cdc } 2}$ or NIMA. We therefore investigated the negative control of these two mitosispromoting kinases after DNA damage. DNA damage caused rapid Tyr15 phosphorylation of $\mathrm{p}^{\text {cdc } 2}$ and transient cell cycle arrest but had little effect on the activity of NIMA. Dividing cells deficient in Tyr15 phosphorylation of $\mathrm{p}^{24^{c d 2}}$ were sensitive to both MMS and UV irradiation and entered lethal premature mitosis with damaged DNA. However, non-dividing quiescent conidiospores of the Tyr15 mutant strain were not sensitive to DNA damage. The UV and MMS sensitivity of cells unable to tyrosine phosphorylate $\mathrm{p34}^{c d c 2}$ is therefore caused by defects in DNA damage checkpoint regulation over mitosis. Both the nimA5 and nimT23 temperature-sensitive mutations cause an arrest in $G_{2}$ at $42^{\circ} \mathrm{C}$. Addition of MMS to nimT23 $\mathbf{G}_{2-}$ arrested cells caused a marked delay in their entry into mitosis upon downshift to $32^{\circ} \mathrm{C}$ and this delay was correlated with a long delay in the dephosphorylation and activation of $\mathrm{p}^{c d c 2}$. Addition of MMS to $\operatorname{nimA5} \mathrm{G}_{2}$-arrested cells caused inactivation of the $\mathrm{H1}$ kinase activity of $\mathrm{p34}^{c d c 2}$ due to an increase in its Tyr15 phosphorylation level and delayed entry into mitosis upon return to $32^{\circ} \mathrm{C}$. However, if Tyr15 phosphorylation of $\mathrm{p}^{c d c 2}$ was prevented then its $\mathrm{H} 1$ kinase activity was not inactivated upon MMS addition to $\operatorname{nim} A 5 \mathrm{G}_{2}$-arrested cells and they rapidly progressed into a lethal mitosis upon release to $32^{\circ} \mathrm{C}$. Thus, Tyr15 phosphorylation of $\mathrm{p34}^{c d c 2}$ in $\mathrm{G}_{2}$ arrests initiation of mitosis after DNA damage in A.nidulans.

Keywords: Aspergillus/DNA damage checkpoint/ $\operatorname{nim} X^{c d c 2} /$ Tyr 15 phosphorylation of $\mathrm{p} 34^{c d c 2}$

\section{Introduction}

DNA damage causes a $G_{2}$ delay of the cell cycle in eukaryotic cells (Hartwell and Weinert, 1989; Carr; 1995; Kaufmann, 1995; Murray, 1995). This $\mathrm{G}_{2}$ delay presumably allows cells enough time to repair damaged DNA before initiation of mitosis. The dependency of initiation of mitosis on completion of DNA damage repair is established by $\mathrm{G}_{2} / \mathrm{M}$ DNA damage checkpoints. The first direct genetic link between the $\mathrm{G}_{2}$ checkpoint regulation and DNA damage was demonstrated with rad9 mutations in budding yeast. Strains carrying rad9 mutations are deficient in $\mathrm{G}_{2}$ delay after DNA damage, and thus enter lethal premature mitosis in the presence of damaged DNA (Weinert and Hartwell, 1988). Many genes involved in the $G_{2} / M$ DNA damage checkpoint regulation were subsequently identified in both budding and fission yeasts by screening for mutations which uncouple initiation of mitosis from $\mathrm{G}_{2}$ delay after DNA damage (Al-Khodairy and Carr, 1992; Allen et al., 1994; Weinert et al., 1994). Many of these checkpoint genes have now been cloned. However, the cell cycle targets for the checkpoint regulation to bring about $\mathrm{G}_{2}$ delay in response to DNA damage remain to be established (Carr, 1995; Murray, 1995; Lydall and Weinert, 1996).

The activation of the universally conserved $\mathrm{p} 34^{c d c 2} \mathrm{H} 1$ kinase, the mitosis-promoting factor (MPF), is central to the timing and initiation of mitosis in all eukaryotic cells (Draetta, 1990; Nurse, 1990; Murray, 1992; Dunphy, 1994; Osmani et al., 1994). The activation of $\mathrm{p} 34^{c d c 2}$ requires association with the regulatory subunit cyclinB which accumulates during late $\mathrm{S}$-phase and $\mathrm{G}_{2}$ (Evans et al., 1983; Booher et al., 1989), and the phosphorylation of Thr161 by CDC2-activating kinase (CAK) (Fesquet et al., 1993; Poon et al., 1993; Solomon et al., 1993). During S and $\mathrm{G}_{2}$ the $\mathrm{p} 34^{c d c 2}$-cyclinB complex is kept in the inactive pre-MPF state through Tyr15 phosphorylation of $\mathrm{p} 34^{c d c 2}$ by Wee1/Mik1/Myt1 tyrosine kinases (Russell and Nurse, 1987; Gould and Nurse, 1989; Lungren et al., 1991; Parker and Piwnica-Worms, 1992; Mueller et al., 1995). During the $\mathrm{G}_{2} / \mathrm{M}$ transition the pre-MPF form of $\mathrm{p} 34^{c d c 2}$ is rapidly converted into the active MPF form by Tyr15 dephosphorylation catalyzed by the Cdc 25 tyrosine phosphatase (Russell and Nurse, 1986; Kumagai and Dunphy, 1991). The major regulatory event for the final activation of $\mathrm{p} 34^{c d c 2}$ during mitotic initiation thus appears to be the rapid dephosphorylation at Tyr15. Therefore, Tyr15 phosphorylation of $\mathrm{p} 34^{c d c 2}$ could be a target for negative regulation by the $\mathrm{G}_{2} / \mathrm{M}$ DNA damage checkpoint control systems.

Elevated levels of Tyr15-phosphorylated p34cdc2 are found to be associated with $\mathrm{G}_{2}$-arrested cells after DNA damage in several systems (Kharbanda et al., 1994; O'Conor et al., 1994; Herzinger et al., 1995; Barth et al., 1996). However, the significance of Tyr15 phosphorylation of $\mathrm{p} 34^{c d c 2}$ in the $\mathrm{G}_{2} / \mathrm{M}$ DNA damage checkpoint regulation remains to be established in these systems. The regulatory pathway for $\mathrm{p} 34^{c d c 2}$ tyrosine phosphorylation/dephosphorylation and its role in cell cycle regulation are best characterized in fission yeast (Russell and Nurse, 1986, 1987; Gould and Nurse, 1989; Lungren et al., 1991). Fission yeast cells unable to tyrosine phosphorylate p34 $4^{c d c 2}$ advance mitosis and produce small 'wee' cells (Gould and Nurse, 1989; Lungren et al., 1991). These mutant cells enter mitosis even when DNA replication is inhibited (Enoch and Nurse, 1990; Lungren et al., 1991). Thus, 
Tyr 15 phosphorylation of $\mathrm{p} 34^{c d c 2}$ links initiation of mitosis to completion of DNA replication in fission yeast. However, the role of such phosphorylation in the $\mathrm{G}_{2} / \mathrm{M}$ DNA damage checkpoint regulation is not well understood. Fission yeast cells deficient in Wee1 function are sensitive to DNA damage by UV and gamma irradiation (AlKhodairy and Carr, 1992; Rowley et al., 1992). In addition, Rowley et al. (1992) reported that the DNA damage checkpoint in fission yeast is mediated through the Weel protein kinase as fission yeast cells deficient in Wee1 function lack a significant mitotic delay after gamma irradiation. However, Barbet and Carr (1993) subsequently showed that fission yeast cells defective or lacking in Wee1 function have a normal mitotic arrest after DNA damage. The Tyr15 phosphorylation state and $\mathrm{H} 1$ kinase activity of $\mathrm{p} 34^{c d c 2}$ in response to DNA damage, however, were not analyzed biochemically in these studies. Thus, the role of Tyr15 phosphorylation of p34 $4^{c d c 2}$ in the $\mathrm{G}_{2} / \mathrm{M}$ DNA damage checkpoint regulation remains to be firmly established in fission yeast through a combination of both biochemical and genetic studies. However, such a role in response to DNA damage has recently been established in human cells (Jin et al., 1996). On the other hand, both DNA replication and DNA damage checkpoints are fully operative in budding yeast cells unable to tyrosine-phosphorylate p34 ${ }^{c d c 28}$ (Amon et al., 1992; Sorger and Murray, 1992; Stueland et al., 1993), conclusively demonstrating that in this system S-phase and $\mathrm{G}_{2} / \mathrm{M}$ checkpoint regulations inhibit mitosis by some other mechanism.

In Aspergillus nidulans, coordinate activation of two mitosis-promoting kinases is required for the initiation of mitosis (Osmani et al., 1991a; Ye et al., 1995). One is the universally conserved $\mathrm{p} 34^{c d c 2} \mathrm{H} 1$ kinase encoded by the nimX gene (Osmani et al., 1994). The regulatory pathway for p34 ${ }^{c d c 2}$ activation is also conserved in A.nidulans (Osmani et al., 1991a, 1994; O'Connell et al., 1992; P.Ramos, X.Ye, R.Fincher, S.Osmani and L.Ellis, in preparation). The other essential mitosis-promoting kinase is the NIMA kinase which is currently well characterized only in A.nidulans (for review, see Osmani and Ye, 1996). However, indirect evidence indicates that a NIMA-like mitotic pathway may also exist in fission yeast, Хеnopus and human cells (O’Connell et al., 1994; Lu and Hunter, 1995). Unlike most mitotic regulatory functions which regulate $\mathrm{p} 34^{c d c 2} \mathrm{H} 1$ kinase activity, NIMA kinase is required for initiation of mitosis independently of the regulation of $\mathrm{p} 34^{c d c 2} \mathrm{H} 1$ kinase activity (Osmani et al., 1991a).

We recently uncovered two overlapping S-phase checkpoint mechanisms over the initiation of mitosis in A.nidulans (Ye et al., 1996). The first, the slowing of S-phase checkpoint, monitors the rate of DNA replication and, when DNA replication is slowed, prevents mitosis temporarily through Tyr15 phosphorylation of $\mathrm{p} 34^{c d c 2}$. Thus, when DNA replication is slowed, cells deficient in tyrosine phosphorylation of $\mathrm{p} 34^{c d c 2}$ enter mitosis prematurely. The second, the S-phase arrest checkpoint, requires both BIME function and Tyr15 phosphorylation of $\mathrm{p} 34^{c d c 2}$ which in combination inactivate NIMA kinase and cause inhibition of mitosis when DNA replication is actually halted. Thus, cells lacking either Tyr15 phosphorylation of $\mathrm{p} 34^{\text {cdc2 }}$ (Ye et al., 1996) or the function of BIME (Osmani et al., 1988, 1991b; James et al., 1995) have a limited capacity to initiate mitosis when DNA replication

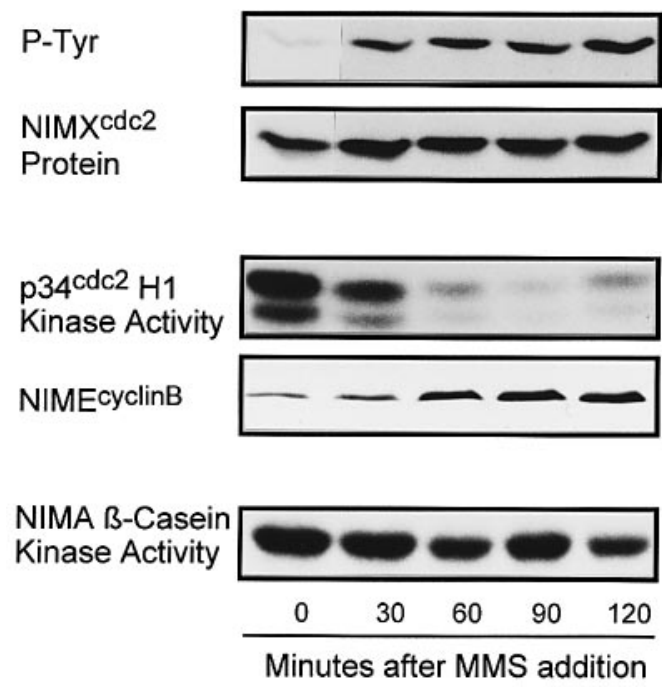

Fig. 1. Effects of DNA damage by MMS on p34 ${ }^{c d c 2}$ and NIMA kinases. MMS $(0.04 \%)$ was added to an exponentially growing wildtype (strain R153) culture. Samples were taken at 30 min intervals after MMS addition, and NIMA and $\mathrm{p} 34^{c d c 2}$ kinase activities were analyzed. The level of Tyr15-phosphorylated $\mathrm{p} 34^{c d c 2}$ was determined by Western blotting using a monoclonal anti-phosphotyrosine antibody after immunoprecipitation of $\mathrm{p} 34^{c d c 2}$. After P-Tyr detection the blot was stripped and the protein level of $\mathrm{p} 34^{c d c 2}$ in the immunoprecipitates was detected using E-77 anti-NIMX ${ }^{c d c 2}$ antisera.

is stopped. Only cells lacking both Tyr15 phosphorylation of $\mathrm{p} 34^{c d c 2}$ and the function of BIME are able to activate NIMA precociously and initiate mitosis effectively from S-phase in the absence of DNA replication (Ye et al., 1996).

In this study we examined the relationship between Tyr15 phosphorylation of $\mathrm{p} 34^{c d c 2}$ and $\mathrm{G}_{2}$ delay caused by DNA damage in A.nidulans. We found that A.nidulans cells unable to Tyr15-phosphorylate $\mathrm{p} 34^{c d c 2}$ were deficient in the DNA damage-mediated $\mathrm{G}_{2}$ delay and entered mitosis prematurely after DNA damage. Consequently, only dividing cells deficient in Tyr 15 phosphorylation of $\mathrm{p} 34^{c d c 2}$ were sensitive to DNA damage. Thus, Tyr15 phosphorylation of $\mathrm{p} 34^{c d c 2}$ in $\mathrm{G}_{2}$ alone links initiation of mitosis to completion of DNA damage repair in A.nidulans.

\section{Results}

\section{MMS increases the level of Tyr15-phosphorylated p34 ${ }^{\text {cdc2 }}$}

Methyl methanesulfonate (MMS) causes effective DNA damage in A.nidulans (Kafer and Mayor, 1986), the addition of $0.01 \%$ MMS to germinating wild-type conidia delaying the first mitosis for more than $4 \mathrm{~h}$. The first mitosis of germinating conidiospores normally occurs between 5.5 and $6.5 \mathrm{~h}$ after germination at $32^{\circ} \mathrm{C}$, whereas the first mitosis of MMS-treated germinating conidiospores did not occur until 9-10 h (data not shown, see also Figure 3). This suggests that a DNA damage checkpoint mechanism operates in A.nidulans, the activation of which causes a delay of entry into mitosis.

To investigate if either (or both) of the mitosis-producing kinases, $\mathrm{p} 34^{c d c 2}$ or NIMA, are targets of the DNA damage checkpoint mechanism, we first determined the biochemical effects of addition of MMS to an exponentially growing wild-type culture. Addition of MMS only slightly inhibited NIMA kinase activity (Figure 1). We previously 
demonstrated that NIMA is a target for the negative regulation by $S$-phase checkpoints via both Tyr15 phosphorylation of $\mathrm{p} 34^{c d c 2}$ and the function of BIME (Ye et al., 1996). Activation of S-phase checkpoints by the DNA synthesis inhibitor hydroxyurea (HU) rapidly inactivates the NIMA kinase (Ye et al., 1996). Here, lack of strong inhibition of NIMA by DNA damage suggests that NIMA is not a primary target for the DNA damage checkpoint system.

In contrast, addition of MMS caused rapid Tyr15 phosphorylation of p34 $4^{c d c 2}$ (Figure 1), the level of phosphorylation increasing markedly $30 \mathrm{~min}$ after MMS addition. Even though the level of NIME ${ }^{\text {cyclinB }}$ increased, $\mathrm{p} 34^{c d c 2} \mathrm{H} 1$ kinase activity was reduced after MMS addition (Figure 1). Thus, the DNA damage checkpoint could delay mitosis by inhibition of $\mathrm{p} 34^{c d c 2}$ through Tyr15 phosphorylation.

\section{Dividing cells deficient in Tyr15 phosphorylation of p34 ${ }^{c d c 2}$ are sensitive to UV irradiation and MMS because they enter mitosis prematurely with damaged DNA}

If the DNA damage checkpoint is indeed mediated through Tyr 15 phosphorylation of $\mathrm{p} 34^{c d c 2}$, dividing cells unable to undergo such phosphorylation should be sensitive to DNAdamaging agents, as cells deficient in DNA damage checkpoint regulation would be unable to restrain cell cycle progression and would enter lethal premature mitosis in the presence of damaged DNA. Non-dividing cells deficient in $\mathrm{p} 34^{c d c 2}$ Tyr15 phosphorylation, on the other hand, should not be sensitive to DNA-damaging agents as they would not be able to undergo a lethal premature mitosis but would be able to repair damaged DNA. We recently generated a nim $X^{c d c 2 A F}$ mutant strain, in which p34 ${ }^{c d c 2}$ cannot be tyrosine-phosphorylated, using a twostep gene replacement technique after in vitro mutagenesis of nimX $X^{c d c 2}$ (Ye et al., 1996). We therefore checked the sensitivity of dividing and non-dividing nim $X^{c d c 2 A F}$ cells to UV irradiation. Wild-type and DNA damage repairdeficient $u v s H 4^{\mathrm{rad} 18}$ (Kafer and Mayor, 1986; Yoon et al., 1995) strains were used as controls.

When UV irradiation was applied to quiescent conidiospores, the $n i m X^{c d c 2 A F}$ mutant strain was no more sensitive to UV irradiation than the wild-type (Figure 2A). The nim $X^{c d c 2 A F}$ conidiospores must therefore be able to repair DNA damage during the process of germination before they initiate mitosis after entering the cell cycle from $\mathrm{G}_{1}$ arrest. On the other hand, the $u v s H 4^{\mathrm{rad} 18}$ strain, as previously reported (Kafer and Mayor, 1986), was extremely sensitive to UV irradiation, and was completely killed by a $100 \mathrm{~J} / \mathrm{m}^{2}$ dose which only slightly affected the wildtype and $n i m X^{c d c 2 A F}$ strains (Figure $2 \mathrm{~A}$ ). The data suggest that, unlike the DNA repair-deficient $u v s H 4^{\mathrm{rad} 18}$ strain, the nim $X^{c d c 2 A F}$ mutant has no deficiency in DNA damage repair mechanisms.

In contrast, germinating $n i m X^{c d c 2 A F}$ conidiospores were sensitive to UV irradiation (Figure 2B). In this experiment conidiospores were first allowed to germinate for $4.5 \mathrm{~h}$ before UV irradiation was applied, and by which time they had entered the first cell cycle. As the $\operatorname{nim} X^{c d c 2 A F}$ mutant cells attempt the first mitosis earlier than the wildtype (Ye et al., 1996; see also Figure 3), we checked whether the difference in UV sensitivity between the wild- type and the $n i m X^{c d c 2 A F}$ mutant strains was caused by the different cell cycle stages at which the UV irradiation was applied. However, when germinating conidiospores of the wild-type strain were irradiated by UV at various times after germination, their survival rate was very similar to that shown in Figure 2B. Thus, UV sensitivity of dividing nim $X^{c d c 2 A F}$ mutant cells is likely to be caused specifically by deficient DNA damage checkpoint regulation.

As MMS addition to a growing culture caused rapid Tyr15 phosphorylation and reduced the $\mathrm{H} 1$ kinase activity of p34 $4^{c d c 2}$ (Figure 1), we expected that the $\operatorname{nim} X^{c d c 2 A F}$ mutant cells would also be sensitive to MMS. As shown in Figure 2C and $\mathrm{D}$, the $\operatorname{nim} X^{c d c 2 A F}$ strain was indeed much more sensitive to MMS than the wild-type, measured either as reduction in survival rate or in colony size in the presence of various concentrations of MMS incorporated into the medium.

To confirm directly that the nim $X^{c d c 2 A F}$ mutant was deficient in the DNA damage checkpoint control, we determined the kinetics of entry into mitosis of germinating conidiospores in the presence of a low concentration of MMS. In the absence of MMS the chromosome mitotic index $(\mathrm{CMI} \%)$ of the wild-type strain began to rise at $5 \mathrm{~h}$ and peaked at $6.5 \mathrm{~h}$ after germination (Figure 3). Addition of MMS to the germinating medium of the wild-type strain completely inhibited mitosis for up to $7 \mathrm{~h}$ after germination (Figure 3).

As previously demonstrated (Ye et al., 1996), nim $X^{c d c 2 A F}$ mutant cells entered mitosis earlier than the wild-type cells (Figure 3). Addition of MMS delayed but did not stop the nim $X^{c d c 2 A F}$ mutant cells progressing into mitosis (Figure 3). By $7 \mathrm{~h}$ after germination, $>50 \%$ of the nim $X^{c d c 2 A F}$ mutant cells entered mitosis, whereas none of the wild-type cells attempted mitosis in the presence of MMS (Figure 3). These data show that the nim $X^{c d c 2 A F}$ mutant strain is deficient in the DNA damage checkpoint regulation, as it entered mitosis prematurely in the presence of damaged DNA, thus exhibiting increased sensitivity to DNA-damaging agents.

Addition of MMS, however, did cause a delay of progression into mitosis in the $\operatorname{nim} X^{c d c 2 A F}$ germinating conidiospores (Figure 3). Such delay may be caused by non-specific cytotoxic effects of MMS, although addition of MMS may have activated additional checkpoint mechanisms. As germinating conidiospores enter the cell cycle from $G_{1}$, candidates for such additional checkpoint mechanisms are the $\mathrm{G}_{1} / \mathrm{S}$ checkpoints which transiently delay entry into S-phase after DNA damage, as demonstrated in the budding yeast (Siede et al., 1993, 1994; Lydall and Weinert, 1996).

We demonstrated previously that Thr14 phosphorylation cooperates with Tyr15 phosphorylation in the negative regulation of $\mathrm{p} 34^{c d c 2}$ in response to the S-phase checkpoint control (Ye et al., 1996). Thus, the strain bearing both $\mathrm{T} 14 \mathrm{~A}$ and $\mathrm{Y} 15 \mathrm{~F}$ mutations of $n i m X^{c d c 2}$ demonstrates greater sensitivity to $\mathrm{HU}$ than does the strain with only the Y15F mutation (Ye et al., 1996). To investigate whether Thr14 phosphorylation of $\mathrm{p} 34^{c d c 2}$ also had a role in the DNA damage checkpoint regulation, we compared the UV sensitivity of germinating conidiospores derived from various mutant strains (Ye et al., 1996). The strain bearing the T14A mutation alone showed a wild-type level of sensitivity to UV (Figure 2E). Unlike the sensitivity to 
A

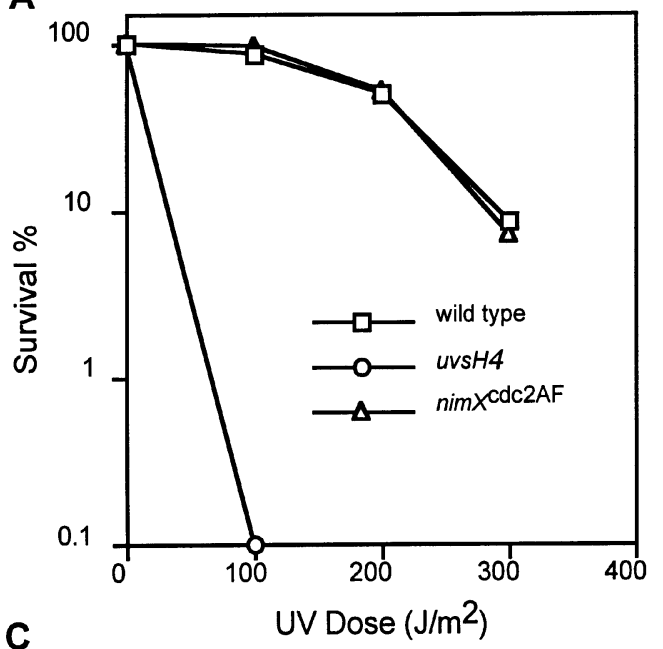

C

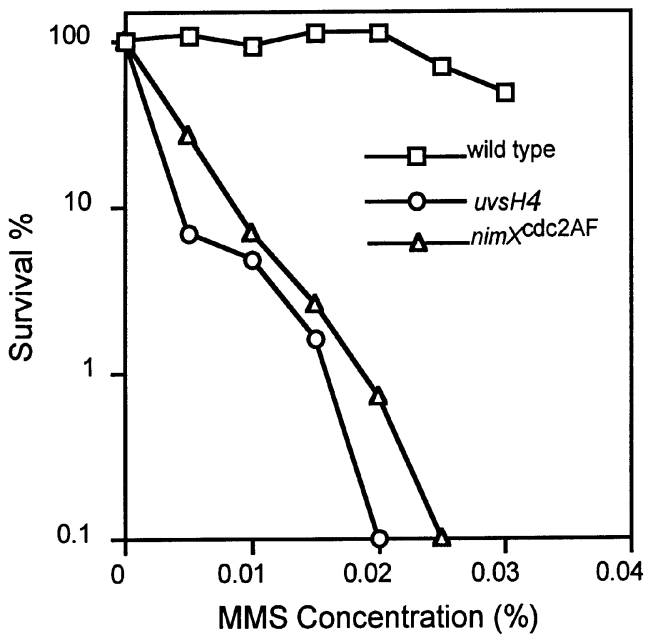

B

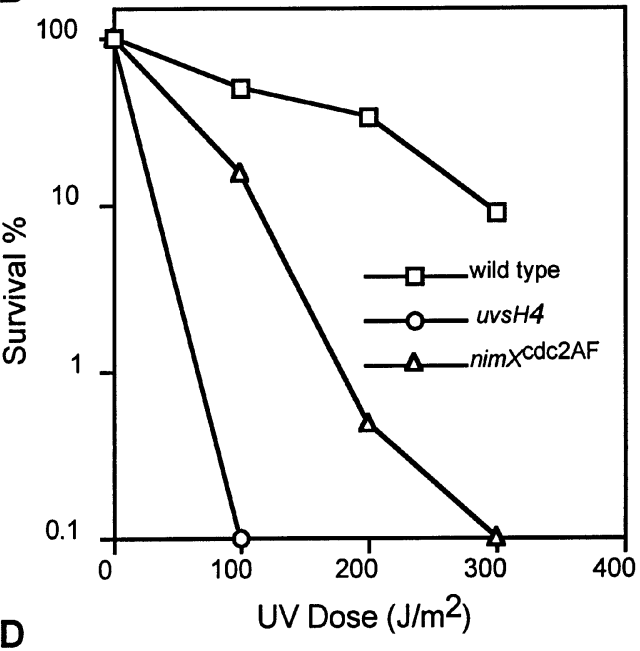

D

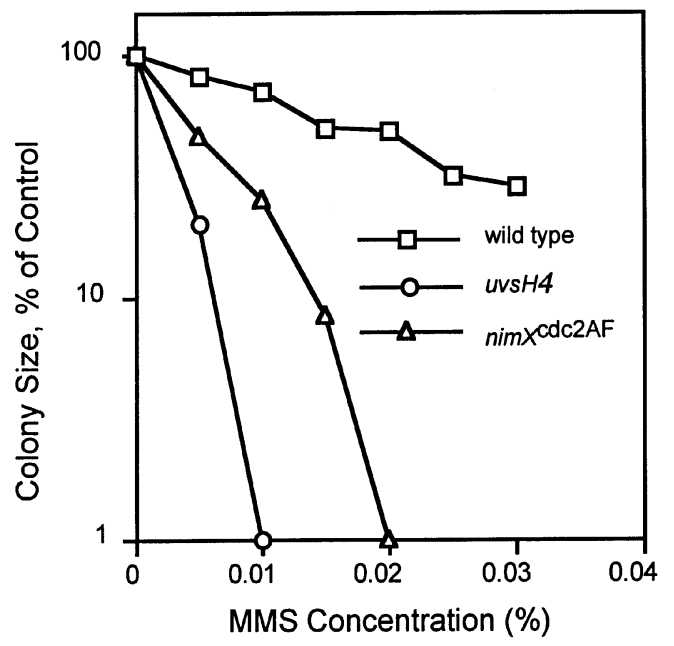

E

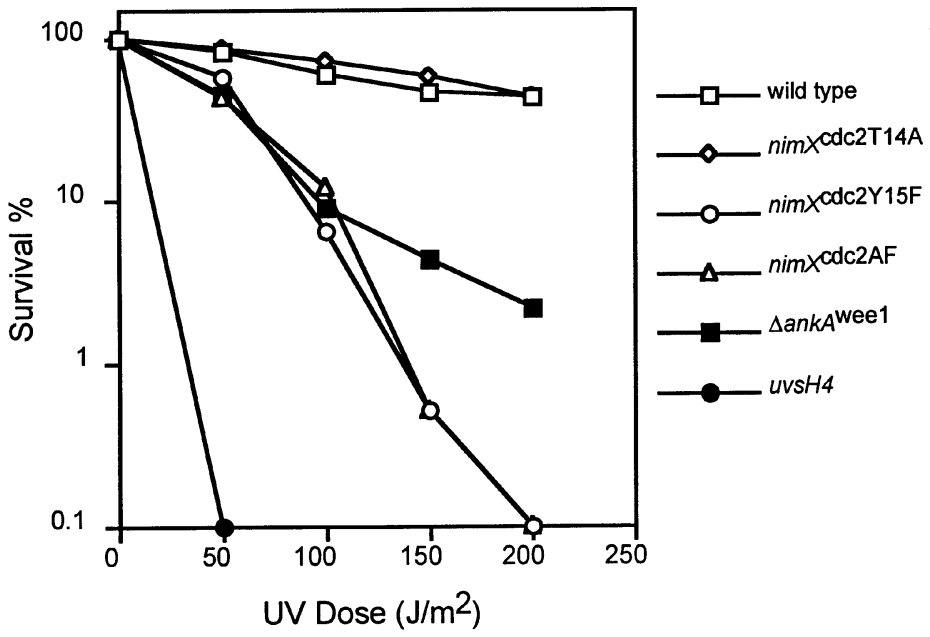

Fig. 2. UV and MMS sensitivity of strains deficient in Tyr15 phosphorylation of $\mathrm{p} 34^{c d c 2}$. Conidiospores ( 250 spores/plate) of a wild-type and nim $X^{c d c 2 A F}$ strain were spread out onto YAG plates. The plates were either immediately UV irradiated (A) or incubated at $32^{\circ} \mathrm{C}$ for $4.5 \mathrm{~h}$ to allow spore germination and were then UV irradiated (B). After UV irradiation the plates were incubated at $32^{\circ} \mathrm{C}$ for 2 days for colony formation. To test sensitivity of the strains to MMS, conidiospores (250 spores/plate) were spread out on YAG plates containing various concentrations of MMS (C). The survival rate of the strains after DNA damage either by UV irradiation or by MMS incorporated into the medium was expressed as percentage of colonies produced by control conidiospores in the absence of treatment. In addition the strains were spot-inoculated onto MMS-containing YAG plates to assess colony growth (D). The colony size was measured 3 days after inoculation and effect of MMS on colony growth was expressed as a percentage of colony size of their respective controls without MMS. The survival rate of various mutant strains affecting the inhibitory phosphorylation status of p34 $4^{c d c 2}$ after UV irradiation (E). UV irradiation was applied $4.5 \mathrm{~h}$ after germination as for (B). 


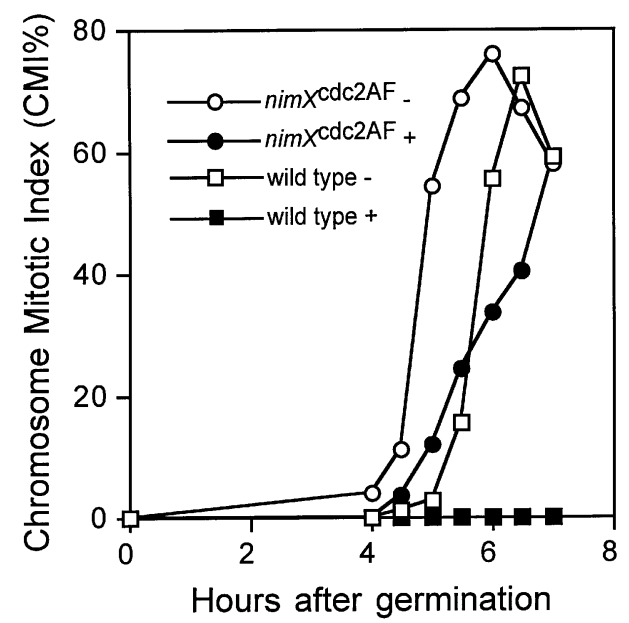

Fig. 3. $n i m X^{c d c 2 A F}$ mutations promote mitosis prematurely in the presence of DNA damage. Conidiospores of the wild-type and nim $X^{c d c 2 A F}$ strains were germinated in YG medium containing $5 \mu \mathrm{g} / \mathrm{ml}$ nocodazole and $0.01 \%$ MMS. Nocodazole was added to trap cells in mitosis in order to facilitate the determination of the rate at which cells entered mitosis. Samples were taken at the time intervals indicated, fixed and stained with DAPI. CMI\% is shown as percentage of germinated spores with condensed chromatin. -, absence of MMS; + , presence of MMS

HU, the strain bearing both T14A and Y15F mutations did not have more UV sensitivity than did the strain with the Y15F mutation alone, and similar results were obtained using MMS as the DNA-damaging agent (data not shown). Thus, Thr14 phosphorylation of $\mathrm{p} 34^{c d c 2}$ appears to have no role in the DNA damage checkpoint regulation, at least in response to UV and MMS. As previously demonstrated for HU sensitivity of the strains (Ye et al., 1996), MMS sensitivity caused by the Tyr 15 mutation of $\mathrm{p} 34^{c d c 2}$ is also dominant over the endogenous wild-type nimX $X^{c d c 2}$. The strain with $\Delta a n k A^{\text {weel }}$ was also found to be UV (Figure 2E) and MMS sensitive (data not shown). Thus the DNA damage checkpoint in A.nidulans in response to UV and MMS is likely to be mediated through Tyr15 phosphorylation of $\mathrm{p} 34^{c d c 2}$.

\section{DNA damage by MMS delays entry into mitosis during nimT23 ${ }^{\text {cdc25 }}$ block-release by delaying Tyr15 dephosphorylation of p34 ${ }^{c d c 2}$}

The major DNA damage checkpoint in both budding and fission yeasts operates during the $G_{2} / M$ transition preventing initiation of mitosis in the presence of damaged DNA (Hartwell and Weinert, 1989; Carr, 1995; Lydall and Weinert, 1996). To address the role of Tyr15 phosphorylation of $\mathrm{p} 34^{c d c 2}$ in the $\mathrm{G}_{2} / \mathrm{M}$ DNA damage checkpoint control specifically, we utilized $\mathrm{G}_{2}$-specific temperature-sensitive mutations to synchronize cells at $\mathrm{G}_{2}$ by temperature upshift before causing DNA damage with MMS, and then observed the relationship between Tyr15 phosphorylation of $\mathrm{p} 34^{c d c 2}$ and the initiation of mitosis upon return of the cells to permissive temperature.

Inactivation of NIMT ${ }^{c d c 25}$, a homolog of the fission yeast $\mathrm{p} 34^{c d c 2}$-specific tyrosine phosphatase $\mathrm{Cdc} 25$, blocks cells at $\mathrm{G}_{2}$ (Figure $4 \mathrm{~B},-\mathrm{MMS}$ ). At the arrest point, p34 $4^{c d c^{2}}-$ cyclinB accumulates as inactive pre-MPF in which p3 $4^{c d c 2}$ is phosphorylated at both Tyr15 and Thr161 (Figure $4 \mathrm{~A}$ and $\mathrm{C}, \mathrm{G}_{2}$ sample). In exponentially-growing cells, p34 $4^{c d c 2}$ is present in two states, seen as two bands on Western blots (Figure 4A and C, EX. cells). The fastermigrating band of $\mathrm{p} 34^{c d c 2}$ is associated with NIME $\mathrm{E}^{\mathrm{cyclinB}}$ and is phosphorylated at Thr161 or at both Thr161 and Tyr15 (Osmani et al., 1994; Ye et al., 1996). Upon release to permissive temperature, cells entered a rapid and synchronous mitosis with peak CMI at 10-15 min (Figure 4B, -MMS; Ye et al., 1995) as p34 $4^{c d c 2}$ became rapidly tyrosine-dephosphorylated and activated. As previously reported (Ye et al., 1995), NIMA and NIME ${ }^{\text {cyclinB }}$ accumulated at the nimT23 $3^{c d c 25} \mathrm{G}_{2}$ arrest point, and the NIMA kinase became fully activated and hyperphosphorylated after activation of $\mathrm{p} 34^{c d c 2}$ by tyrosine dephosphorylation (Figure 4A). As cells progressed through mitosis, both NIMA and NIME ${ }^{\text {cyclinB }}$ were degraded, leading to the down-regulation of the two mitosis-promoting kinases. When NIME ${ }^{\text {cyclinB }}$ was degraded, some p34 ${ }^{\text {cdc2 }}$ became dephosphorylated at Thr161 and was thus converted to the non-phosphorylated slower-migrating band on Western blot (Figure 4A and C).

MMS was added to the nimT23 $3^{c d c 25} \mathrm{G}_{2}$-arrested cells for $75 \mathrm{~min}$ to cause transient DNA damage and then removed from the culture by fresh medium exchange as cells were down-shifted to release the $\mathrm{G}_{2}$ block. Addition of MMS to nimT23 $3^{c d c 25} \mathrm{G}_{2}$-arrested cells markedly delayed entry into mitosis after return to $32^{\circ} \mathrm{C}$ (Figure $4 \mathrm{~B}$, + MMS). This mitotic delay was correlated with delayed activation of $\mathrm{p} 34^{c d c 2}$ by tyrosine dephosphorylation (Figure 4C) and $\mathrm{p} 34^{c d c 2}$ remained Tyr15-phosphorylated for $1 \mathrm{~h}$ compared with only 5 min without MMS addition (Figure 4A). NIME $E^{\text {cyclinB }}$ accumulated at the $\operatorname{nim} T 23^{\operatorname{cdc} 25} \mathrm{G}_{2}$ arrest point and remained stable during the MMS-induced mitotic delay (Figure 4C). As p34 ${ }^{c d c 2}$ became transiently activated by Tyr 15 dephosphorylation between 60 and 70 min after release (Figure 4C) cells concurrently underwent a largely synchronous mitosis with peak CMI at 70 min (Figure 4B). Then, the level of NIME ${ }^{\text {cyclinB }}$ was reduced, and $\mathrm{p} 34^{c d c 2}$ kinase activity was down-regulated, as cells progressed through mitosis (Figure $4 \mathrm{~B}$ and $\mathrm{C}$ ). These data clearly demonstrate a strong correlation between $\mathrm{G}_{2}$ delay and Tyr15 phosphorylation of p34 $4^{c d c 2}$ after DNA damage caused by addition of MMS.

\section{Inactivation of p34 ${ }^{c d c 2}$ by Tyr15 phosphorylation after DNA damage by MMS prevents rapid entry into mitosis upon release of the nimA5 mutation}

Previous studies have demonstrated that NIMA is required for mitotic initiation by a mechanism that does not involve activation of $\mathrm{p} 34^{c d c 2} \mathrm{H} 1$ kinase activity (Osmani et al., 1991a; Ye et al., 1996). For example, inactivation of NIMA does not prevent full activation of $\mathrm{p} 34^{c d c 2} \mathrm{H} 1$ kinase activity and inactivation of NIMA prevents mitotic initiation even when $\mathrm{p} 34^{c d c 2}$ is fully activated and cannot be Tyr15 phosphorylated (Ye et al., 1996; Figures 5A and 6). In fact, upon release of cells from the nim $A 5 \mathrm{G}_{2}$ arrest point, the levels of $\mathrm{p} 34^{c d c 2} \mathrm{H} 1$ kinase activity are seen to decrease as cells are entering mitosis (Figure 5A). We therefore asked whether the activated $\mathrm{p} 34^{c d c 2}$ present at the nimA $5 \mathrm{G}_{2}$ arrest point is inactivated upon DNA damage by MMS. As can be seen in Figure 5B, and as expected, p3 $4^{c d c 2}$ activity increased when cells were arrested in $G_{2}$ due to inactivation of NIMA. However, upon addition of MMS, p34 ${ }^{c d c 2}$ activity was severely inhibited and it was 
A

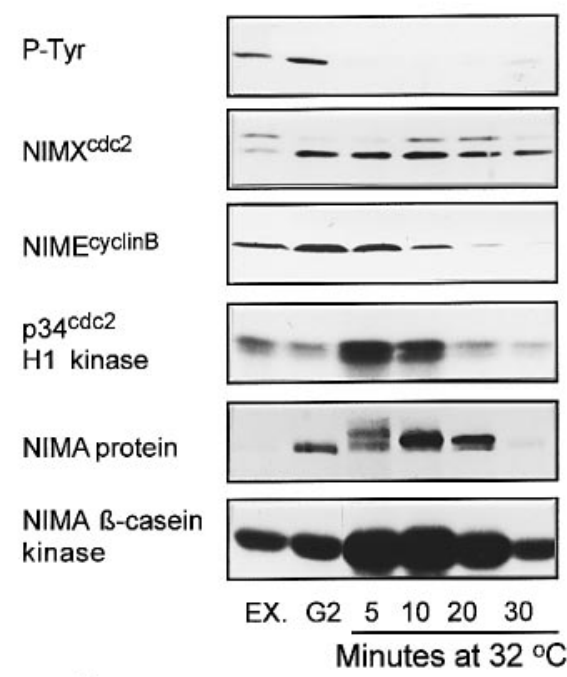

B

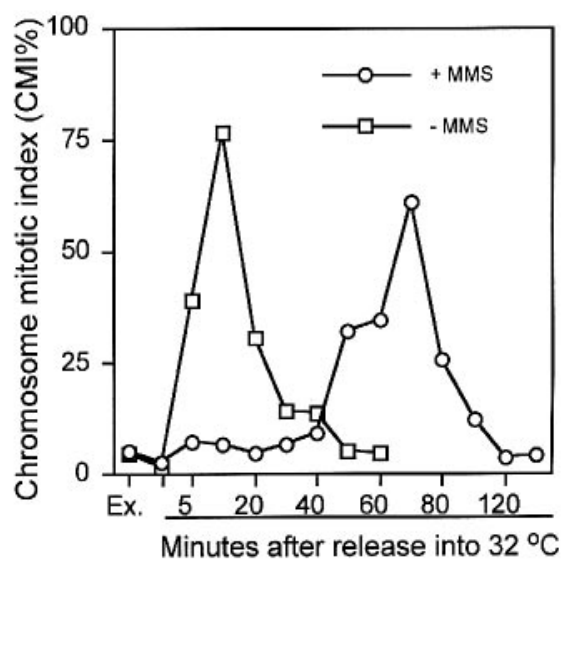

C

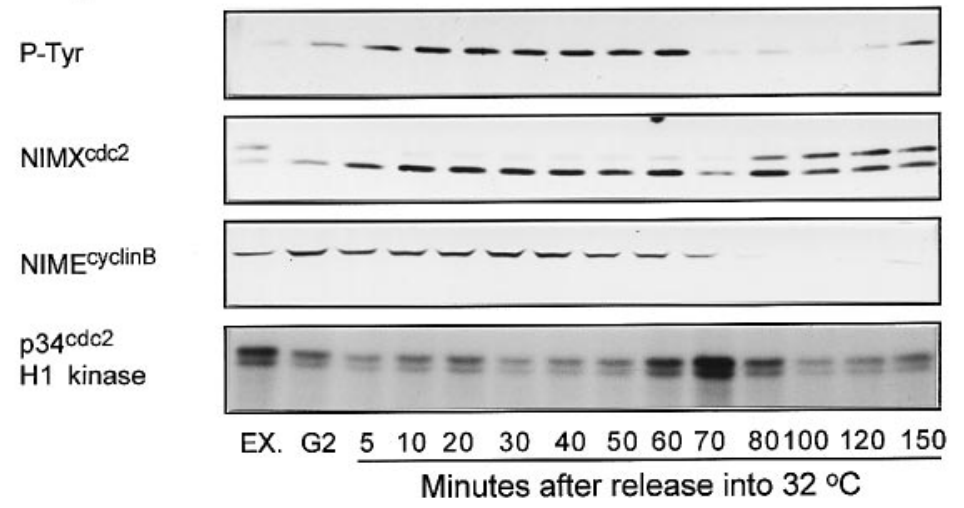

Fig. 4. nimT23 $3^{c d c 25}$ block-release experiment in the presence and absence of MMS. (A) nimT23 $3^{c d c 25}$ block-release in the absence of MMS addition. (B) Chromosome mitotic index (CMI\%) during nimT23 ${ }^{\text {cdc } 25}$ block-release with or without MMS addition. (C) nimT23 ${ }^{\text {cdc } 25}$ block-release in the presence of MMS addition. An early log phase culture of $n i m T 23^{c d c 25}$ was upshifted to the restrictive temperature of $42^{\circ} \mathrm{C}$ to inactivate NIMTcdc25 and cause cell cycle arrest at the nimT23 ${ }^{\text {cdc } 25} \mathrm{G}_{2}$ arrest point. MMS was added to the $\mathrm{G}_{2}$-arrested culture to a final concentration of $0.04 \%$ at $2.5 \mathrm{~h}$ after temperature upshift and was removed from the culture $75 \mathrm{~min}$ after addition by exchange with fresh medium prewarmed to $42^{\circ} \mathrm{C}$. The culture was then released from the $\mathrm{G}_{2}$ arrest into permissive temperature of $32^{\circ} \mathrm{C}$. For the control culture in the absence of MMS, cells were blocked for the same period of time $(3.25 \mathrm{~h})$ at $42^{\circ} \mathrm{C}$ as for the MMS-treated culture before release into permissive temperature to allow the initiation of synchronous mitosis. Samples were taken at the time points indicated for CMI\%, and for biochemical analysis.

Tyr15-phosphorylated (Figure 5B). Normally, release of cells from the nimA5 $\mathrm{G}_{2}$ arrest point allows cells rapidly to enter mitosis (Figure 5A). However, after MMS addition there was a long $\mathrm{G}_{2}$ delay as $\mathrm{p} 34^{c d c 2}$ remained Tyr15phosphorylated and largely inactivated. These cells eventually entered a partially synchronous mitosis as the level of Tyr15 phosphorylation decreased (Figure 5B). During the $\mathrm{G}_{2}$ delay caused by MMS addition, the level of NIME ${ }^{\text {cyclinB }}$ increased and virtually all p34 $4^{c d c 2}$ was phosphorylated on the activating Thr161 site (faster-migrating band on NIMX ${ }^{c d c 2}$ Western blot, Figure 5B). Thus, the $\mathrm{G}_{2}$ delay after DNA damage is not mediated through regulation of either NIME ${ }^{\text {cyclinB }}$ levels or CAK activity but instead correlates well with Tyr15 phosphorylation of $\mathrm{p} 34^{c d c 2}$.

In summary, nimT23 $3^{c d c 25}$ and nimA5 mutations arrest cells in $\mathrm{G}_{2}$ at restrictive temperature either before $\left(\operatorname{nim} T 23^{c d c 25}\right)$ or after (nimA5) activation of $\mathrm{p} 34^{c d c 2}$ and generate rapid synchronous mitosis upon release into permissive temperature. Addition of MMS to nimT23 $3^{c d c 25}$ and $\operatorname{nimA5} \mathrm{G}_{2}$-arrested cells caused a marked delay of entry into mitosis after release of the $\mathrm{G}_{2}$ arrests. This mitotic delay caused by MMS was correlated with Tyr 15 phosphorylation of $\mathrm{p} 34^{c d c 2}$.

\section{Cells unable to tyrosine-phosphorylate p34cdc2 lack the $G_{2}$ delay after DNA damage and enter mitosis prematurely}

To demonstrate directly whether Tyr15 phosphorylation of $\mathrm{p} 34^{c d c 2}$ was responsible for the DNA damage-induced $\mathrm{G}_{2}$ delay, we repeated the nimA5 block-release experiments with or without MMS addition using nimA5 + $\triangle a n k A^{\text {wee } 1}$ and nimA5 $+n i m X^{c d c 2 A F}$ double mutants. As expected, the double mutants were still arrested in $\mathrm{G}_{2}$ at the restrictive temperature for the nimA5 mutation, although p34 ${ }^{c d c 2}$ cannot be Tyr15-phosphorylated (Ye et al., 1996; Figure 6). Upon release into permissive temperature, the double-mutant strains both rapidly underwent a similar synchronous mitosis (Figure 6,-MMS). This $\mathrm{G}_{2}$ arrest using the nimA5 mutation therefore enabled us to analyze directly the consequence of lack of $\mathrm{p} 34^{c d c 2}$ tyrosine 
A

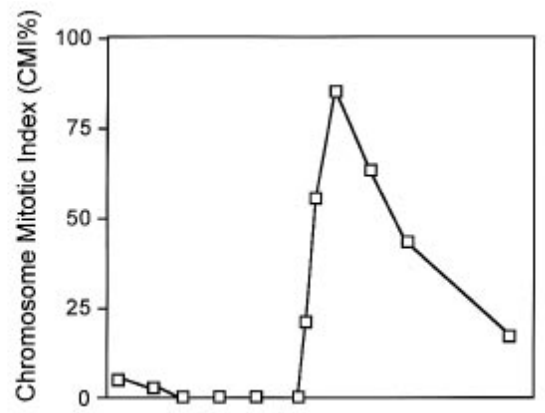

NIMA protein

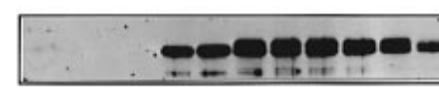

NIMA Kinase

p34cdc2 $\mathrm{H} 1$ Kinase Activity

NIMEcyclinB protein
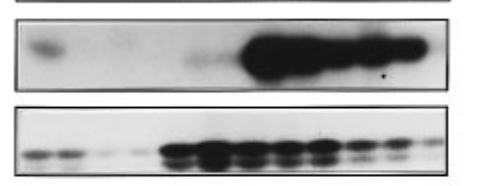

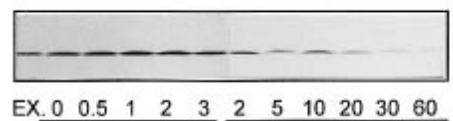

Hours at $42{ }^{\circ} \mathrm{C}$ Minutes after release

B

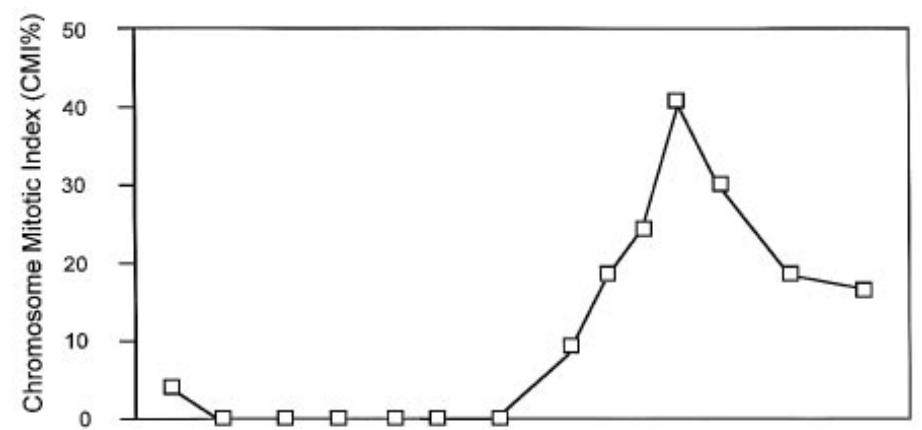

P-Tyr

NIMXcdc2

Protein

p34 cdc2 $\mathrm{H} 1$

Kinase Activity

NIMEcyclinB
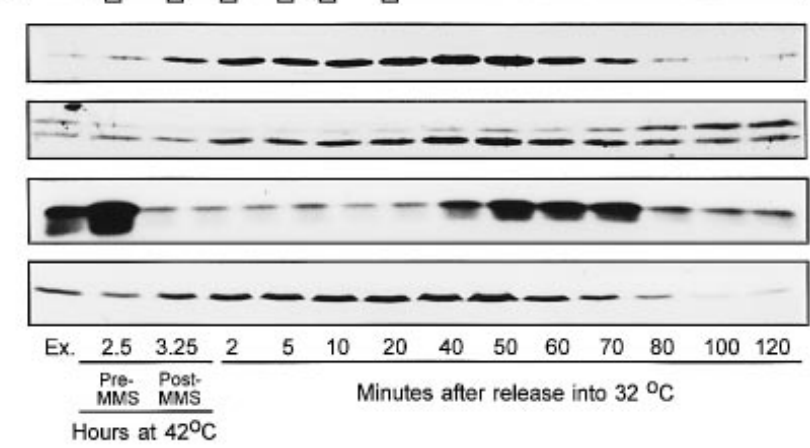

Fig. 5. nimA5 block-release experiment in the presence and absence of MMS. nimA5 block-release with or without MMS was carried out as for nimT $23^{c d c 25}$ block-release described in Figure 4. (A) nimA5 block-release in the absence of MMS addition. (B) nimA5 block-release in the presence of MMS addition.

phosphorylation during a synchronized mitosis in the presence of damaged DNA.

Addition of MMS to nimA5 $\mathrm{G}_{2}$-arrested cells markedly delayed entry into mitosis (Figure 6). If the $a n k A^{\text {weel }}$ gene was deleted, this $\mathrm{G}_{2}$ delay was partially overcome (Figure 6) and a partially synchronous mitosis of the nimA5 + $\triangle a n k A^{\text {weel }}$ strain occurred $\sim 30$ min earlier than the nimA5 single mutant strain. However, if the putative inhibitory phosphorylation sites, T14 and Y15, of p34 ${ }^{c d c 2}$ ( nimX $^{c d c 2}$ ) were mutated to non-phosphorylatable $\mathrm{A}$ and $\mathrm{F}$ residues respectively (nimX $X^{c d c 2 A F}$ ), this $\mathrm{G}_{2}$ delay was then completely overcome (Figure 6). Furthermore, p34 ${ }^{c d c 2} \mathrm{H} 1$ kinase activity remained high after MMS addition in the nim $X^{c d c 2 A F}$ mutant cells (data not shown). Thus, the $\mathrm{G}_{2}$ delay after DNA damage was mediated through Tyr15 phosphorylation of $\mathrm{p} 34^{c d c 2}$.

The partial override of the MMS-induced $\mathrm{G}_{2}$ delay by $\Delta a n k A^{\text {weel }}$ suggests the existence of a mikl homolog in A.nidulans. This likelihood is further indicated as $\triangle a n k A^{\text {weel }}$ only partially complements the nimT $23^{\text {cdc } 25}$ mutation, whereas non-Tyr15-phosphorylated p34 ${ }^{c d c 2}$ (nimX $X^{c d c 2 Y 15 F}$ or $n i m X^{c d c 2 A F}$ ) completely complements nimT23 ${ }^{c d c 25}$ (P.Ramos, X.Ye, R.Fincher, S.Osmani and L.Ellis, in preparation).

To determine the consequence of the premature mitosis caused by $\operatorname{nim} X^{c d c 2 A F}$ after DNA damage in the above block-release experiments, we compared the viability of the single nimA5 and the nimA5 + nim $X^{c d c 2 A F}$ doublemutant cells. As shown in Figure 7, cells of either the nimA5 or nimA5 $+\operatorname{nim} X^{c d c 2 A F}$ double-mutant strains remained viable after nimA5 block-release in the absence of MMS treatment. With the addition of MMS, the viability of the single nimA5 mutant cells was slightly reduced. In contrast, a major reduction in viability of the doublemutant cells was observed. Thus, A.nidulans cells unable to tyrosine-phosphorylate $\mathrm{p} 34^{c d c 2}$ are deficient in the
$\mathrm{G}_{2} / \mathrm{M}$ DNA damage checkpoint control. The mutant cells undergo premature lethal mitosis in the presence of damaged DNA and thus exhibit increased sensitivity to DNAdamaging agents.

\section{Discussion}

In this study we have demonstrated that A.nidulans cells have a DNA damage checkpoint mechanism operating during the $G_{2} / M$ transition to restrain progression into mitosis if cellular DNA is damaged. Furthermore, we have established that this $\mathrm{G}_{2} / \mathrm{M}$ DNA damage checkpoint is mediated through Tyr15 phosphorylation of $\mathrm{p} 34^{c d c 2}$ to bring about $\mathrm{G}_{2}$ delay of entry into mitosis. A role for the inhibitory phosphorylation of $\mathrm{p} 34^{c d c 2}$ in radiation-induced $\mathrm{G}_{2}$ arrest has also recently been demonstrated in human cells (Jin et al., 1996). In A.nidulans the NIMA kinase is also required for the initiation of mitosis and has a role in the S/M checkpoint regulation (Ye et al., 1996). However, we found that NIMA does not have a role in the $\mathrm{G}_{2} / \mathrm{M}$ DNA damage checkpoint regulation. The relationship between the $\mathrm{G}_{2} / \mathrm{M}$ DNA damage checkpoint regulation and Tyr15 phosphorylation of $\mathrm{p} 34^{c d c 2}$ is shown in Figure 8.

The cellular level of Tyr15-phosphorylated $\mathrm{p} 34^{c d c 2}$ is regulated by two opposing enzymatic activities. The Wee 1 tyrosine kinase specifically phosphorylates Tyr15, and Cdc25 tyrosine phosphatase specifically dephosphorylates Tyr15 of p34 $4^{c d c 2}$. In A.nidulans the Tyr 15 phosphorylation/ dephosphorylation of $\mathrm{p} 34^{c d c 2}\left(\mathrm{NIMX}^{c d c 2}\right)$ is carried out by ANKA $^{\text {weel } 1}$ and NIMT ${ }^{c d c 25}$, homologs of fission yeast Wee1 and Cdc25 respectively (O'Connell et al., 1992; P.Ramos, X.Ye, R.Fincher, S.Osmani and L.Ellis, in preparation). The activities of Wee1 and Cdc25 are cell cycle-regulated (Izumi et al., 1992; Kumagai and Dunphy, 1992; Tang et al., 1993; for a review, see Maller, 1994). During 


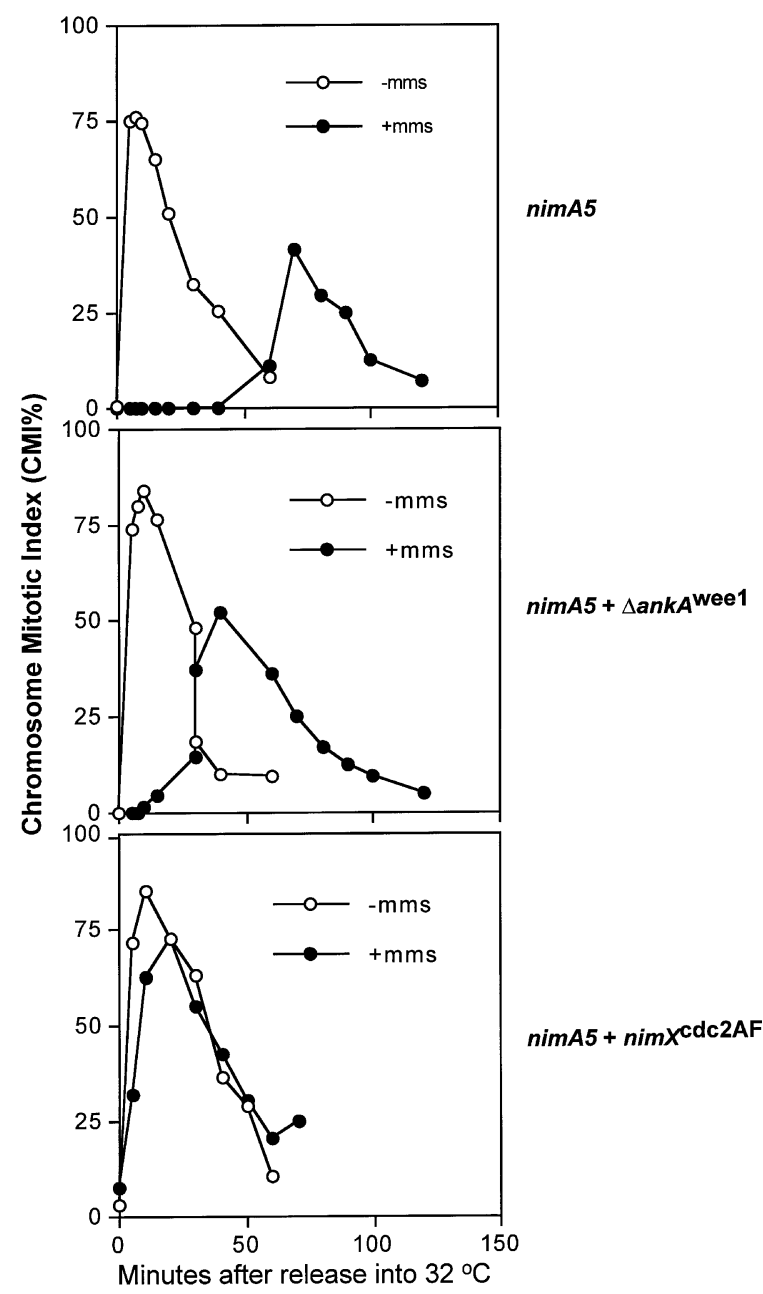

Fig. 6. Chromosome mitotic index (CMI\%) of the nimA5, and $n i m A 5+\triangle a n k A^{\text {weel }}$ or $\operatorname{nim} A 5+\operatorname{nim} X^{c d c 2 A F}$ double-mutant strains during nimA5 block-release in the presence or absence of MMS addition. Conidiospores of the nimA5, and nimA5 $+\triangle a n k A^{\text {weel }}$ or nimA5 + nim $X^{c d c} 2 A F$ double-mutant strains were germinated for $8 \mathrm{~h}$ at the restrictive temperature of $42^{\circ} \mathrm{C}$ for the $\operatorname{nim} A 5$ mutation. MMS was then added to the culture and then removed by medium exchange 75 min after addition; cells were then released immediately into permissive temperature. Cell samples were taken at the indicated time points after release, fixed and stained with DAPI. Chromosome mitotic index was determined as percentage of cells with condensed chromatin.

interphase, the Wee1 kinase activity is high, whereas $\mathrm{Cdc} 25$ phosphatase activity is low. Thus, p34 cdc2 $\mathrm{H} 1$ kinase accumulates in the Tyr15-phosphorylated, inactive preMPF form during interphase. During the $\mathrm{G}_{2} / \mathrm{M}$ transition Cdc25 phosphatase activity is abruptly activated and Wee1 kinase inactivated, thus leading to rapid Tyr15 dephosphorylation and activation of $\mathrm{p} 34^{c d c 2} \mathrm{H} 1$ kinase. It is believed that Wee1, Cdc25 and p34 ${ }^{c d c 2} \mathrm{H} 1$ kinase are all in a feedback loop in which activation of p34 $4^{c d c 2}$ further activates itself through feedback activation of Cdc25 and inhibition of Wee1 (King et al., 1994; Maller, 1994). However, this regulatory circuit of $\mathrm{p} 34^{c d c 2}$ activation is apparently not essential during a normal cell cycle progression in A.nidulans as cells deficient in Tyr15 phosphorylation of $\mathrm{p} 34^{c d c 2}$ are viable (Ye et al., 1996 and the present study).

At present, it is not understood how the DNA damage

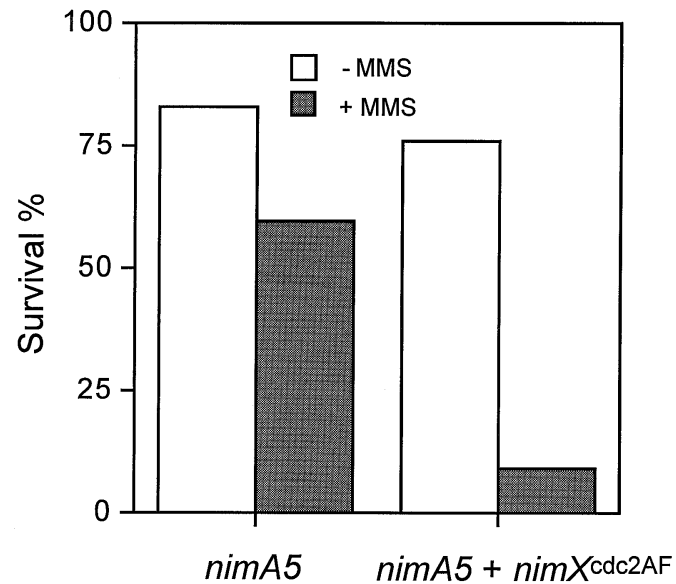

Fig. 7. Cell viability of the nimA5 single and the $\operatorname{nim} A 5+\operatorname{nim} X^{c d c 2 A F}$ double-mutant strains during a nimA5 block-release in the presence or absence of MMS addition. The nimA5 temperature block-release and MMS addition were carried out exactly as described for Figure 6. After release from the nimA5 $\mathrm{G}_{2}$ arrest MMS was removed and germlings were plated out on YAG plates for colony formation. Cell viability was then assessed as percentage of colonies formed by the same number of conidiospores without temperature block-release and MMS addition.

\section{DNA damage checkpoint}

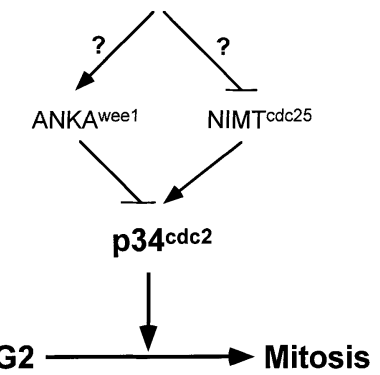

Fig. 8. Model showing the relationship between Tyr15 phosphorylation of $334^{c d c 2}$ and the initiation of mitosis mediated by the $\mathrm{G}_{2} / \mathrm{M}$ DNA damage checkpoint.

checkpoint in A.nidulans regulates p34 $4^{c d c 2}$ activation to keep $\mathrm{p} 34^{c d c 2}$ Tyr15-phosphorylated during response to DNA damage. This could be achieved by either activating the ANKA ${ }^{\text {weel }}$ kinase or inactivating the NIMT ${ }^{c d c 25}$ phosphatase, or both. Certainly ANKA wee1 kinase is required for the $\mathrm{G}_{2} / \mathrm{M}$ DNA damage checkpoint regulation because ANKA $^{\text {wee } 1}$ is the major tyrosine kinase that phosphorylates p34 ${ }^{c d c 2}$ at Tyr15 (P.Ramos, X.Ye, R.Fincher, S.Osmani and L.Ellis, in preparation). Moreover, $\triangle \mathrm{ANKA}^{\text {wee } 1}$ cells are DNA damage checkpoint-deficient and are sensitive to DNA-damaging agents. However, whether the DNA damage checkpoint regulates ANKA $^{\text {wee } 1}$ kinase activity directly is currently not known.

The results of nimT23 $3^{c d c 25}$ block-release with MMS addition suggest that NIMT ${ }^{c d c 25}$ may be inactivated by the DNA damage checkpoint. Normally NIMT ${ }^{c d c 25}$ is very rapidly activated upon release from nimT23 $3^{c d c 25} \mathrm{G}_{2}$ arrest as p34 ${ }^{c d c 2}$ becomes Tyr15-dephosphorylated and activated within 5 min after release (Figure 4A). However, p34 $4^{c d c 2}$ remains highly Tyr15-phosphorylated for $1 \mathrm{~h}$ after release if MMS is added to cause transient DNA damage to the nimT23 $3^{c d c 25} \mathrm{G}_{2}$-arrested cells (Figure 4C). If activation of NIMT $^{c d c 25}$ is indeed prevented during this temperature 
block-release in response to DNA damage, then $\mathrm{p} 34^{c d c 2}$ would remain Tyr15-phosphorylated. The inactivation of Cdc25C phosphatase activity has been implicated in $\mathrm{G}_{2}$ arrest in response to DNA damage in human cells (O'Conor et al., 1994; Barth et al., 1996). However, we cannot exclude the possibility that high activation of ANKA ${ }^{\text {weel }}$ after DNA damage could act to counteract the normal activation of NIMT ${ }^{c d c 25}$.

At the $\operatorname{nim} A 5 \mathrm{G}_{2}$ arrest point, $\mathrm{p} 34^{c d c 2}$ is already activated by Tyr15 dephosphorylation (Figure 5A; Osmani et al., 1991a). According to the positive feedback loop scheme of p34 ${ }^{c d c 2}$ activation (King et al., 1994; Maller, 1994), activated $\mathrm{p} 34^{c d c 2}$, as seen at the $\operatorname{nimA5} \mathrm{G}_{2}$ arrest point, would generate fully activated NIMT ${ }^{c d c 25}$ but inactive $\mathrm{ANKA}^{\text {wee } 1}$. If this regulatory scheme is active in A.nidulans then the ANKA $^{\text {weel }}$ kinase would be inactive at the nimA5 $\mathrm{G}_{2}$ arrest point as $\mathrm{p} 34^{c d c 2}$ is activated. DNA damage would then have to lead to some activation of $\mathrm{ANKA}^{\text {wee } 1}$, or an equivalent kinase, in order to cause Tyr15 phosphorylation of $\mathrm{p} 34^{c d c 2}$. In addition to the studies presented here, DNA damage by MMS can also effectively cause Tyr15 phosphorylation and inactivation of $\mathrm{p} 34^{c d c 2}$ in cells blocked in mitosis (X.Ye, R.Fincher, A.Tang and S.Osmani, unpublished data). This suggests that in A.nidulans checkpoint systems that monitor successful progression through mitosis could also be mediated through inactivation of p34 $4^{c d c 2}$ by Tyr15 phosphorylation. It will be of interest to see how $\mathrm{ANKA}^{\text {weel }}$ and $\mathrm{NIMT}^{c d c 25}$ are regulated in response to DNA damage at different periods of the cell cycle to ascertain their respective roles in the inhibition of $\mathrm{p} 34^{c d c 2}$ at different cell cycle stages.

We recently demonstrated that Tyr 15 phosphorylation of p34 ${ }^{c d c 2}$ has a role in two overlapping S-phase checkpoint mechanisms in A.nidulans, one involving both Tyr15 phosphorylation of $\mathrm{p} 34^{c d c 2}$ and the function of BIME (Ye et al., 1996). How is Tyr15 phosphorylation of $\mathrm{p} 34^{c d c 2}$ involved in both the $S$-phase checkpoint and the $\mathrm{G}_{2} / \mathrm{MDNA}$ damage checkpoint regulation? The simplest explanation is that although cells may use different mechanisms to detect unreplicated DNA and DNA damage, the signals generated in response to such detections may converge upon the same cell cycle target, that is, inhibition of p34 $4^{c d c 2}$ by Tyr15 phosphorylation. In addition, these two checkpoint mechanisms may actually overlap as they both monitor, and respond to, the state of DNA, and therefore may share common components of a checkpoint signal transduction pathway leading to Tyr15 phosphorylation of $\mathrm{p} 34^{c d c 2}$. This hypothesis is supported by the observations that A.nidulans cells bearing mutations in $u v s B$ or $u v s D$, which were originally isolated as UV irradiation-sensitive mutants (Jansen, 1970; Fortuin, 1971), are deficient not only in S-phase checkpoint control but also in the $G_{2} / M$ DNA damage checkpoint control (X.Ye, A.Tang, R.Fincher and S.Osmani, unpublished results). Similarly, several genes have been identified in fission yeasts that are required for both $\mathrm{S}$-phase and $\mathrm{G}_{2} / \mathrm{M}$ checkpoint controls (Carr, 1995) and these functions may also influence the Tyr15 phosphorylation state of $\mathrm{p} 34^{c d c 2}$, although this has not as yet been tested. Although tyrosine phosphorylation of p34 ${ }^{c d c 28}$ has no role in S-phase or DNA damage checkpoint controls in budding yeast, several genes which have overlapping functions in both $\mathrm{S}$-phase and $\mathrm{G}_{2} / \mathrm{M}$ DNA damage checkpoint controls have also been identified in this system (Murray, 1995; Lydall and Weinert, 1996). The target of these genes to cause cell cycle arrest after DNA damage or inhibition of DNA replication remains to be identified.

In addition to identifying the $\mathrm{G}_{2} / \mathrm{M}$ DNA damage checkpoint system mediated through Tyr15 phosphorylation of $\mathrm{p} 34^{c d c 2}$, the present results also suggest that A.nidulans cells may have a p34 ${ }^{c d c 2}$ Tyr15 phosphorylation-independent DNA damage checkpoint system operating in earlier stages of the cell cycle. This hypothesis is based on the observation that although non-Tyr15phosphorylated p34 $4^{c d c 2}$ mutant cells completely overcome the MMS-induced $\mathrm{G}_{2}$ delay (Figure 6), the same mutant cells show a delay of progression into mitosis when germinated from $\mathrm{G}_{1}$ in the presence of MMS (Figure 3). There are at least two possible levels of control that may mediate this delay after DNA damage that do not rely on Tyr15 phosphorylation of $\mathrm{p} 34^{c d c 2}$. In mammalian cells, p53 is known to be required for the DNA damage-induced $\mathrm{G}_{1}$ arrest, partly through a mechanism involving p53dependent induction of the CDK inhibitor p21 (Kaufmann, 1995; Lydall and Weinert, 1996). In addition, DNA damage may cause a slowing or arrest of DNA replication which could then impose S-phase checkpoint regulation over mitosis (Lamb et al., 1989; Paulovich and Hartwell, 1995). If DNA damage does lead to impaired DNA replication in A.nidulans it is unlikely that this would lead to our observed delay in mitosis in the $\operatorname{nim}^{c d c 2 A F}$ mutant strain germinated in the presence of MMS, as the slowing of S-phase checkpoint over mitosis is defective in this strain (Ye et al., 1996). If germination in MMS leads to an arrest of the initiation of S-phase, or causes its delay, then the arrest of S-phase checkpoint could be operative as this level of control involves not only Tyr15 phosphorylation of $334^{c d c 2}$ but also the function of bimE (Ye et al., 1996). Future studies will determine if $\operatorname{bim} E$ plays a role in DNA damage checkpoint control in $\mathrm{G}_{1}$ and $\mathrm{S}$-phase.

In conclusion, A.nidulans cells have a $\mathrm{G}_{2} / \mathrm{M}$ DNA damage checkpoint mechanism and the major cell cycle target for this checkpoint regulation is Tyr15 phosphorylation of $\mathrm{p} 34^{c d c 2}$. In response to DNA damage the checkpoint control rapidly inhibits cell cycle progression into mitosis by inactivating $\mathrm{p} 34^{c d c 2} \mathrm{H} 1$ kinase through Tyr15 phosphorylation, presumably allowing time for DNA damage repair in $G_{2}$ before initiation of mitosis. Having established the cell cycle targets for the S-phase checkpoints (Ye et al., 1996) and for the DNA damage checkpoint we can now begin to delineate the signal transduction pathways leading to Tyr15 phosphorylation of $\mathrm{p} 34^{c d c 2}$ in response to inhibition of DNA replication and to DNA damage in A.nidulans.

\section{Materials and methods}

\section{Aspergillus nidulans strains and general techniques}

A.nidulans strains used in this study were R153 (pyroA4; wA3); SO53 (nimT23 $\left.3^{\text {cdc25 }} ; w A 2\right) ;$ SO54 (nimA5; wA2); $\Delta \mathrm{AnkA}^{\text {weel }}\left(\triangle a n k A^{\text {weel }}\right.$; pyrG89; pyr4+; pyroA4; wA3); FRY2 (nimA5; $\Delta a n k A^{\text {weel }}$; pyrG89; pyr4+; yA2); FRY20 (pNIG6-nimX ${ }^{\text {cdc2AF; }}$; pyr4+ pyroA4; pyrG89; wA3); FRY20-1 (nimX ${ }^{c d c 2 A F}$; pyroA4; pyrG89; wA3); FRY24 (pNIG6-

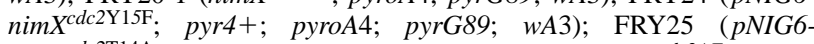

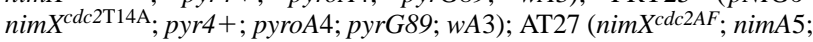
pyroA4; riboA2; wA3); A329 (adE20; biA1; wA3; uvsH4; methG1; pyroA4). Media and general techniques for culture, protein extraction, 
protein immunoprecipitation, NIMA and $\mathrm{p} 34^{c d c 2}$ kinase assays, Western blotting, and DAPI staining for chromosome mitotic index determination were as previously described (Osmani et al., 1987, 1991a, 1994; Oakley and Osmani, 1993; Ye et al., 1995).

\section{Sensitivity test to UV irradiation and MMS}

Non-dividing and dividing cells deficient in Tyr15 phosphorylation of p $34^{c d c 2}$ were tested for sensitivity to UV irradiation. Conidiospores (dormant in a quiescent $\mathrm{G}_{0}$ state) were suspended in $0.2 \%$ Tween-20 and plated out on YAG plates ( 250 spores/plate). The plates were then irradiated immediately with UV using a microprocessor-controlled UV crosslinker (FB-UVXL-1000; Fisher Biotech, Pittsburgh, PA, USA) to determine UV sensitivity of non-dividing cells. To determine UV sensitivity of dividing cells, conidiospores on YAG plates were first allowed to germinate for $4.5 \mathrm{~h}$ at $32^{\circ} \mathrm{C}$ before UV irradiation. By this time the germinated spores had entered the cell cycle and were about to undergo the first mitosis. UV-irradiated germlings were then incubated in a $32^{\circ} \mathrm{C}$ incubator for 2 days for colony formation. The survival rate after UV irradiation was determined as a percentage of colonies produced by control conidiospores without UV irradiation.

In MMS (Aldrich, St Louis, MO, USA) sensitivity tests, various concentrations of MMS were incorporated into YAG medium. To determine the survival rate in the presence of MMS, conidiospores (250 spores/plate) were plated out on YAG plates containing MMS. After a 2 day incubation at $32^{\circ} \mathrm{C}$, the survival rate was determined as the percentage of colonies produced by control conidiospores on YAG plates containing no MMS. MMS sensitivity was also measured by reduction in colony growth. In this case conidiospores were spot-inoculated with tooth-picks onto YAG plates containing MMS.

\section{nimT23 ${ }^{\text {cdc25 }}$ and nimA5 temperature block-release}

nimT $23^{c d c 25}$ and nimA5 mutant cells were first grown to early log phase at $32^{\circ} \mathrm{C}$ and were then rapidly upshifted to the restrictive temperature of $42^{\circ} \mathrm{C}$. After $\mathrm{G}_{2}$ arrest at $42^{\circ} \mathrm{C}$, cells were released into synchronous mitosis by temperature downshift to $32^{\circ} \mathrm{C}$. To determine the effect of MMS on the rapid synchronous mitosis generated by $\operatorname{nim} T 23^{c d c 25}$ and nimA5 block-release, MMS $(0.04 \%)$ was added to the $\mathrm{G}_{2}$-arrested cells $2.5 \mathrm{~h}$ after temperature upshift to $42^{\circ} \mathrm{C}$. After incubation at $42^{\circ} \mathrm{C}$ for a further $75 \mathrm{~min}$, MMS was removed from the culture by medium exchange and cells were then downshifted to permissive temperature of $32^{\circ} \mathrm{C}$.

\section{Cell viability assay after nimA5 block-release}

nimA5 mutant conidiospores were germinated at $42^{\circ} \mathrm{C}$ for $8 \mathrm{~h}$ in $\mathrm{YG}$ medium containing $0.1 \%$ agar to prevent clumping. The germinating spores were arrested in the first cell cycle at the $\operatorname{nimA5} \mathrm{G}_{2}$ arrest point. MMS $(0.04 \%)$ was added to the $\operatorname{nimA5} \mathrm{G}_{2}$-arrested germlings for 75 min to cause DNA damage and was then removed from the culture by medium exchange with fresh YG containing no agar. The germlings were then released from $\operatorname{nim} A 5 \mathrm{G}_{2}$ arrest into the permissive temperature of $32^{\circ} \mathrm{C}$. The germlings were resuspended in $0.2 \%$ Tween-20, plated out ( 250 germlings/plate), and incubated at $32^{\circ} \mathrm{C}$ for colony formation. Cell viability was assessed as the percentage of colonies produced by 250 conidiospores without nimA5 temperature block-release and MMS addition.

\section{Acknowledgements}

We thank Dr L.Ellis and Dr P.Ramos (W.M.Keck Center for Genome Informatics, Institute of Biosciences and Technology, Texas A\&M University) for providing the $\Delta a n k A^{\text {weel }}$ strain. We also thank Elizabeth Oakley and Dr B.R.Oakley for critically reading the manuscript. This work was supported by NIH grant GM42564 and by funds from the Geisinger Clinic Foundation.

\section{References}

Al-Khodairy,F. and Carr,A.M. (1992) DNA repair mutants defining $\mathrm{G}_{2}$ checkpoint pathways in Schizosaccharomyces pombe. EMBO J., 11, 1343-1350.

Allen,J., Zhou,Z., Siede,W., Friedberg,E. and Elledge,S. (1994) The SAD1/RAD53 protein kinase controls multiple checkpoints and DNA damage-induced transcription in yeast. Genes Dev., 8, 2416-2428.

Amon,A., Surana,U., Muroff,I. and Nasmyth,K. (1992) Regulation of p34 $4^{\text {cdc28 }}$ tyrosine phosphorylation is not required for entry into mitosis in S. cerevisiae. Nature, $\mathbf{3 5 5}, 368-371$.

Barbet,N.C. and Carr,A.M. (1993) Fission yeast weel protein kinase is not required for DNA damage-dependent mitotic arrest. Nature, $\mathbf{3 6 4}$, 824-827.

Barth,H., Hoffmann,I. and Kinzel,V. (1996) Radiation with 1 Gy prevents the activation of the mitotic inducers Mitosis-promoting factor (MPF) and cdc25-C in HeLa cells. Cancer Res., 56, 2268-2272.

Booher,R.N., Alfa,C.E., Hyams,J.S. and Beach,D.H. (1989) The fission yeast $\mathrm{cdc} 2 / \mathrm{cdc} 13 / \mathrm{suc} 1$ protein kinase: regulation of catalytic activity and nuclear localization. Cell, 58, 485-497.

Carr,A.M. (1995) DNA structure checkpoints in fission yeast. Semin. Cell Biol., 6, 65-72.

Draetta,G. (1990) Cell cycle control in eukaryotes: molecular mechanisms of cdc2 activation. Trends Biochem. Sci., 15, 378-383.

Dunphy,W.G. (1994) The decision to enter mitosis. Trends Cell Biol., 4 , 202-207.

Enoch,T. and Nurse,P. (1990) Mutation of fission yeast cell cycle control genes abolishes dependence of mitosis on DNA replication. Cell, $\mathbf{6 0}$, 665-673.

Evans,T.E., Rosenthal,J., Youngbloom,K. and Hunt,T. (1983) Cyclin: a protein specified by maternal mRNA in sea urchin eggs that is destroyed at each cleavage division. Cell, 33, 389-396.

Fesquet,D., Labbe,J.C., Derancourt,J., Capony,S.G., Girard,F., Lorca,T., Shuttleworth,J., Doree,M. and Cavadore,J.C. (1993) The MO15 gene encodes the catalytic subunit of a protein kinase that activates cdc2 and other cyclin-dependent kinases (CDK) through phosphorylation of Thr161 and its homologues. EMBO J., 12, 3111-3121.

Fortuin,J.J.H. (1971) Another two genes controlling mitotic intragenic recombination and recovery from UV damage in Aspergillus nidulans, I. UV sensitivity, complementation and location of six mutants. Mutat. Res., 11, 149-162.

Gould,K.L. and Nurse,P. (1989) Tyrosine phosphorylation of the fission yeast $\mathrm{cdc} 2+$ protein kinase regulates entry into mitosis. Nature, $\mathbf{3 4 2}$, $39-45$.

Hartwell,L.H. and Weinert,T.A. (1989) Checkpoints: controls that ensure the order of cell cycle events. Science, 246, 629-634.

Herzinger,T., Funk,J.O., Hillmer,K., Eick,D., Wolf,D.A. and Kind,P. (1995) Ultraviolet B irradiation-induced $\mathrm{G}_{2}$ cell cycle arrest in human keratinocytes by inhibitory phosphorylation of the cdc2 cell cycle kinase. Oncogene, 11, 2151-2156.

Izumi,T., Walker,D.H. and Maller,J.L. (1992) Periodic changes in phosphorylation of the Xenopus cdc25 phosphatase regulate its activity. Mol. Biol. Cell, 3, 927-939.

James,S.W., Mirabito,P.M., Scacheri,P.C. and Morris,N.R. (1995) The Aspergillus nidulans bimE (blocked-in-mitosis) gene encodes multiple cell cycle functions involved in mitotic checkpoint control and mitosis. J. Cell Sci., 108, 3485-3499.

Jansen,G.J.O. (1970) Survival of $u v s B$ and $u v s C$ mutants of Aspergillus nidulans after UV-irradiation. Mutat. Res., 10, 21-32.

Jin,P., Gu,Y. and Morgan,D.O. (1996) Role of inhibitory CDC2 phosphorylation in radiation-induced $\mathrm{G}_{2}$ arrest in human cells. J. Cell Biol., 134, 963-970.

Kafer,E. and Mayor,O. (1986) Genetic analysis of DNA repair in Aspergillus: evidence for different types of MMS-sensitive hyperrec mutants. Mutat. Res., 161, 119-134.

Kaufmann,W.K. (1995) Cell cycle checkpoints and DNA repair preserve the stability of the human genome. Cancer Metastasis Rev., 14, 31-41

Kharbanda,S., Saleem,A., Datta,R., Yuan,Z.-M, Weichselbaum,R. and Kufe,D. (1994) Ionization radiation induces rapid tyrosine phosphorylation of $\mathrm{p} 34^{\mathrm{cdc} 2}$. Cancer Res., 54, 1412-1414.

King,R.W., Jackson,P.K. and Kirschner,M.W. (1994) Mitosis in transition. Cell, 79, 563-571.

Kumagai,A. and Dunphy,W.G. (1991) The cdc25 protein controls tyrosine dephosphorylation of the cdc2 protein in a cell-free system. Cell, $\mathbf{6 4}$, 903-914.

Kumagai,A. and Dunphy,W.G. (1992) Regulation of the cdc25 protein during the cell cycle in Xenopus extracts. Cell, 70, 139-151.

Lamb,J.R., Petit-Frere,C., Broughton,B.B., Lehmann,A.R. and Gree,M.H. (1989) Inhibition of DNA replication by ionizing radiation is mediated by a trans-acting factor. Int. J. Radiat. Biol., 56, 125-130.

Lu,K.P. and Hunter,T. (1995) Evidence for a NIMA-like mitotic pathway in vertebrate cells. Cell, 81, 413-424.

Lungren,K., Walworth,N., Booher,R., Dembski,M., Kirschner,M. and Beach,D. (1991) mikl and weel cooperate in the inhibitory tyrosine phosphorylation of cdc2. Cell, 64, 1111-1122.

Lydall,D. and Weinert,T. (1996) From DNA damage to cell cycle arrest and suicide: a budding yeast perspective. Curr. Opin. Genet. Dev., 6, $4-11$. 
Maller,J.L. (1994) Biochemistry of cell cycle checkpoints at the $G_{2} / M$ and metaphase/anaphase transitions. Semin. Dev. Biol., 5, 183-190.

Mueller,P.R., Coleman,T.R., Kumagai,A. and Dunphy,W.G. (1995) Myt1: a membrane-associated inhibitory kinase that phosphorylates $\mathrm{Cdc} 2$ on both threonine-14 and tyrosine-15. Science, 270, 86-90.

Murray,A.W. (1992) Creative clocks: cell cycle checkpoints and feedback controls. Nature, 359, 599-604.

Murray,A.W. (1995) The genetics of cell cycle checkpoints. Curr. Opin. Genet. Dev., 5, 5-11.

Nurse,P. (1990) Universal control mechanism regulating onset of M-phase. Nature, 344, 503-508.

Oakley,B.R. and Osmani,S.A. (1993) Cell-cycle analysis using the filamentous fungus Aspergillus nidulans. In Fantes,P. and Brooks, R. (eds), The Cell Cycle: A Practical Approach. Oxford University Press, Oxford, UK, pp. 127-142.

O’Connell,M.J., Osmani,A.H., Morris,N.R. and Osmani,S.A. (1992) An extra copy of $n i m E^{\text {cyclinB }}$ elevates pre-MPF levels and partially suppresses mutation of nim $T^{\mathrm{cdc} 25}$ in Aspergillus nidulans. EMBO J., 11, 2139-2149.

O'Connell,M.J., Norbury,C. and Nurse,P. (1994) Premature chromatin condensation upon accumulation of NIMA. EMBO J., 13, 49264937.

O’Conor,P.M., Ferris,D.K., Hoffmann,I., Jackman,J., Draetta,G. and Kohn,K.W. (1994) Role of the cdc25C phosphatase in G2 arrest induced by nitrogen mustard. Proc. Natl Acad. Sci. USA, 91, 9480 9484.

Osmani,A.H., McGuire,S.L. and Osmani,S.A. (1991a) Parallel activation of the NIMA and $\mathrm{p} 34^{\mathrm{cdc} 2}$ cell cycle-regulated protein kinases is required to initiate mitosis in A. nidulans. Cell, 67, 283-291.

Osmani,A.H., O’Donnell,K., Pu,R.T. and Osmani,S.A. (1991b) Activation of the NIMA protein kinase plays a unique role during mitosis that cannot be bypassed by absence of the bimE checkpoint. EMBO J., 10, 2669-2679.

Osmani,A.H., van Peij,N., Mischke,M., O'Connell,M.J. and Osmani,S.A (1994) A single p34 ${ }^{\text {cdc2 }}$ protein kinase $\left(\right.$ nim $X^{\text {cdc2 }}$ ) is required at $\mathrm{G}_{1}$ and $\mathrm{G}_{2}$ in Aspergillus nidulans. J. Cell Sci., 107, 1519-1528.

Osmani,S.A. and Ye,X.S. (1996) Cell cycle regulation in Aspergillus by two protein kinases. Biochem. J., 317, 633-641.

Osmani,S.A., May,G.S. and Morris,N.R. (1987) Regulation of the mRNA levels of $\operatorname{nimA}$, a gene required for the G2-M transition in Aspergillus nidulans. J. Cell Biol., 104, 1495-1504.

Osmani,S.A., Engle,D.B., Doonan,J.H. and Morris,N.R. (1988) Spindle formation and chromatin condensation in cells blocked at interphase by mutation of a negative cell cycle control gene. Cell, 52, 241-251.

Parker,L.L. and Piwnica-Worms,H. (1992) Inactivation of the p34 ${ }^{\text {cdc2 } /}$ cyclinB complex by the human WEE1 tyrosine kinase. Science, 257, 1955-1957.

Paulovich,A. and Hartwell,L. (1995) A checkpoint regulates the rate of progression through $\mathrm{S}$ phase in $S$. cerevisiae in response to DNA damage. Cell, 82, 841-847.

Poon,R.Y.C., Yamashita,K., Adamczewski,J.P., Hunt,T. and Shuttleworth,J. (1993) The cdc2-related protein $\mathrm{p} 40^{\mathrm{MO} 15}$ is the catalytic subunit of a protein kinase that can activate $\mathrm{p} 33^{\mathrm{cdk} 2}$ and $\mathrm{p} 34^{\mathrm{cdc} 2}$ EMBO J., 12, 3123-3132.

Rowley,R., Hudson,J. and Young,P.G. (1992) The wee1 protein kinase is required for radiation-induced mitotic delay. Nature, 356, 353-355.

Russell,P. and Nurse,P. (1986) cdc25 functions as an inducer in the mitotic control of fission yeast. Cell, 45, 145-153.

Russell,P. and Nurse,P. (1987) Negative regulation of mitosis by wee $1^{+}$, a gene encoding a protein kinase homolog. Cell, 49, 559-567.

Siede,W., Friedberg,A.S. and Friedberg,E.C. (1993) RAD9-dependent $\mathrm{G}_{1}$ arrest defines a second checkpoint for damaged DNA in the cell cycle of Saccharomyces cerevisiae. Proc. Natl Acad. Sci. USA, 90, 7985-7989.

Siede,W., Friedberg,A.S., Dianova,I. and Friedberg,E.C. (1994) Characterization of $\mathrm{G}_{1}$ checkpoint control in the yeast Saccharomyces cerevisiae following exposure to DNA-damage agents. Genetics, $\mathbf{1 3 8}$, 271-281.

Solomon,M.J., Harper,J.W. and Shuttleworth,J. (1993) CAK, the p34 $4^{\text {cdc2 }}$ activating kinase, contains a protein identical or closely related to p40 ${ }^{\mathrm{MO15}}$. EMBO J., 12, 3133-3142.

Sorger,P.K. and Murray,A.W. (1992) S-phase feedback control in budding yeast independent of tyrosine phosphorylation of $\mathrm{p} 34^{\mathrm{cdc} 28}$. Nature, 355, 365-367.

Stueland,C.S., Lew,D.J., Cismowski,M.J. and Reed,S.I. (1993) Full activation of $\mathrm{p} 34^{\text {cdc } 28}$ histone $\mathrm{H} 1$ kinase activity is unable to promote entry into mitosis in checkpoint-arrested cells of the yeast Saccharomyces cerevisiae. Mol. Cell. Biol., 13, 3744-3755.

Tang,Z., Coleman,T.R. and Dunphy,W.G. (1993) Two distinct mechanisms for negative regulation of the Wee1 protein kinase. EMBO J., 12, 3427-3436.

Weinert,T.A. and Hartwell,L.H. (1988) The RAD9 gene controls the cell cycle response to DNA damage in Saccharomyces cerevisiae. Science, 241, 317-322.

Weinert,T., Kiser,G. and Hartwell,L. (1994) Mitotic checkpoint genes in budding yeast and the dependence of mitosis on DNA replication and repair. Genes Dev., 8, 652-665.

Ye,X.S., Xu,G., Pu,P.T., Fincher,R.R., McGuire,S.L., Osmani,A.H. and Osmani,S.A. (1995) The NIMA protein kinase is hyperphosphorylated and activated downstream of $\mathrm{p} 34^{\mathrm{cdc} 2} / \mathrm{cyclinB}$ : coordination of two mitosis promoting kinases. EMBO J., 14, 986-994.

Ye,X.S., Fincher,R.R., Tang,A., O’Donnell,K. and Osmani,S.A. (1996) Two S-phase checkpoint systems, one involving the function of both BIME and Tyr15 phosphorylation of p34 ${ }^{\mathrm{cdc} 2}$, inhibit NIMA and prevent premature mitosis. EMBO J., 15, 3599-3610.

Yoon,J.H., Lee,B.J. and Kang,H.S. (1995) The Aspergillus uvsH gene encodes a product homologous to yeast RAD18 and Neurospora UVS2. Mol. Gen. Genet., 248, 174-181.

Received on July 22, 1996; revised on September 23, 1996 